\title{
Baudelaire y Benjamin: la musa enferma y la pérdida del aura
}

\author{
Esther Cohen
}

\begin{abstract}
Este ensayo explora la relación entre Walter Benjamin y la poesía de Baudelaire, así como su vínculo con el pensamiento crítico revolucionario de Blanqui. Baudelaire es, para Benjamin, una de las más profundas fuentes de inspiración de su propia crítica a la modernidad. La reflexión de estos tres autores piensa en alternativas de resistencia al flujo interminable del llamado progreso de la era moderna.
\end{abstract}

Palabras Clave: poesía, pensamiento crítico, Benjamin, Baudelaire, Blanqui.

This essay explores the association between Walter Benjamin and Baudelaire's poetry, as well as the connections with Blanqui's critical and revolutionary thinking. One of the deepest sources of inspiration for Benjamin's criticism on modernity is Baudelaire. These three authors' ideas foresee the consequences of modernity and, at the same time, open up alternatives of resistance to the unending flux of the so called progress. 



\section{Esther Cohen}

Instituto de Investigaciones Filológicas, UNAM

\section{Baudelaire y Benjamin: la musa enferma y la pérdida del aura}

Sí, estas gentes hostigadas por penas domésticas, molidas por el trabajo y atormentadas por la edad, derrengadas y doblándose bajo un montón de desperdicios, vómito indefinido del enorme París.

BAUDELAIRE $^{1}$

En el fondo de los bosques, encerrado bajo estas bóvedas semejantes a las sacristías y catedrales, pienso en nuestras sorprendentes ciudades, y la música prodigiosa que rueda sobre las cumbres me parece la traducción de lamentos humanos.

BAUDELAIRE

${ }^{1}$ Oui, ces gens harcelés de chagrins de ménage, Moulus par le travail et tourmentés par l'âge, Éreintés et pliant sous un tas de débris, Vomissement confus de l'énorme Paris.

La traducción es mía, la versión original en francés proviene de la edición bilingüe de las Obras Completas, 291. 
Él [Baudelaire] es, como ellos, un hombre que ha perdido su experiencia, un moderno.

BENJAMIN

Es sabido que el interés de Walter Benjamin por la poesía de Baudelaire se remonta a los años 1914-1915. Pero no será sino hasta 1935 cuando el "poeta maldito" entre al mundo de Benjamin para no abandonarlo más: de ahora en adelante, el filósofo-crítico se fundirá en una especie de simbiosis narrativa y temática con el poeta, sin dejar de lado al otro gran "avisador de incendios", Kafka, que alertará, no sin un dejo de ironía, sobre la modernidad por-venir. Louis Auguste Blanqui (18051881), el ideólogo de la Comuna de París, será la figura que acercará más los mundos del filósofo y del poeta, aunque será él quien dé un paso adelante para definir lo que significa la historia "moderna", es decir, nada más y nada menos que el propio infierno que se renueva día con día, el eterno retorno de lo mismo, es decir, de los vencedores.

Lo que el ángel de la historia benjaminiano verá en 1940 Blanqui ya lo habrá vislumbrado, al mismo tiempo que Baudelaire, un siglo atrás: Baudelaire pasa a ser entonces, para Benjamin, el filósofo y crítico, el poeta de esa catástrofe de la que tanto hablará en sus Tesis de filosofía de la historia. Será su ángel con las alas abiertas y los ojos desorbitados que miran hacia un horizonte turbio y maloliente, perdido entre "lamentos humanos" y suciedad, entre escombros y "vómito", donde todo lo que la mirada del ángel visualiza es la imagen paradójica del "progreso" (cfr. Benjamin, Tesis). Eso que da comienzo a mediados del siglo XIX y que se coronará en el siglo XX con la gran muestra del "avance" científico y tecnológico — las cámaras de gas y sus crematorios-: hacia allá, al menos como lo plantean Adorno y Horkheimer, nos ha conducido la civilización moderna, tal y como la vivieron Blanqui, Baudelaire y 
Benjamin. De ahí que Benjamin — quien optará por la morfina para poner fin a la travesía de su vida - se convierta para nosotros, ya no como en el caso de Baudelaire, que ve con una lucidez sorprendente el principio de ese "progreso", en un auténtico observador de la hecatombe moderna. Por ello, Benjamin recogerá también la obra de Blanqui y su texto "L'Éternité par les astres" (Blanqui, Maintenant), que el filósofo leyó con gran entusiasmo como lo confirma su carta a Horkheimer de 1938 (Benjamin, The Correspondence, 549). Blanqui, abogado y médico parisino, inspiración y "jefe natural" de la Comuna de París, revolucionario de profesión, puede bien considerarse el responsable de la gran revuelta histórica de 1871, aunque él mismo se encuentra en la cárcel en ese momento. Desde allí, inmovilizado tras las rejas, el Blanqui ausente estará presente en cada uno de los blanquistas que dominarán la escena revolucionaria de la Comuna. Por esta razón, no puede separarse el impacto de la obra y la acción revolucionarias de Blanqui de la escritura benjaminiana; tampoco podemos olvidar que, el propio Baudelaire, seguidor y miembro de la Sociedad Republicana Central, "El club Blanqui", poeta de la modernidad, aparecerá obsesivamente en la obra de Benjamin. Es por ello que este último escribe: "Baudelaire se encuentra tan aislado en el mundo de su época como Blanqui en el mundo de los conspiradores" (Benjamin, Libro de los pasajes, 384). No será casual que el mismo Benjamin, sin dejar de tener a Scholem, Adorno y a Brecht como interlocutores, sea una especie de solitario en medio de la catástrofe del progreso.

Si es verdad, como decía antes, que la Segunda Guerra vio coronarse a este tipo de civilización donde la Historia parece haber sufrido un quiebre brutal e irreversible, que marcó con "cenizas" el siglo xx, no deja de preocuparnos el hecho de que lo que vieron estos, llamémosles "profetas", al inicio de la llamada modernidad, siga siendo un modelo para nuestra vida contemporánea. ¿Acaso entonces Auschwitz no fue un acontecimiento 
único en la historia? ¿Acaso Ruanda, Darfur, Irak, Afganistán, el África negra, las dictaduras latinoamericanas, no son en cierta medida clones desfigurados, aunque igualmente sangrientos de nuestra civilización? ¿Acaso hemos pasado a otra etapa o es, como lo decía Blanqui, el eterno retorno de lo mismo? Baste un ejemplo de los Diarios Íntimos de Baudelaire:

Todo periódico, de la primera línea a la última, no es más que una trama de horrores. Guerras, crímenes, impudicias, torturas, crímenes de príncipes, crímenes de naciones, crímenes de particulares, una borrachera de atrocidad universal $[\ldots]$

Todo en este mundo, suda el crimen: el diario, la muralla y el rostro del hombre.

No comprendo cómo una mano pura pueda tocar un diario sin una convulsión de asco.

(Baudelaire, Diarios intimos, 80).
Tout journal, de la première ligne à la dernière, n'est qu'un tissu d'horreurs. Guerres, crimes, vols, impudicités, tortures, crimes des princes, crimes des nations, crimes de particuliers, une ivresse d'atrocité universelle $[\ldots]$

Tout, en ce monde, sue le crime: le journal, la muraille et le visage de l'homme.

Je ne comprends pas qu'une main pure puisse toucher un journal sans une convulsion de dégoût.

(Baudelaire, Journaux intimes, "Mon cœur mis à nu", 158) ${ }^{2}$

Si el poeta es capaz de ver con esa claridad lo que significa la aparentemente ansiada modernidad, ¿qué podemos decir nosotros, en pleno siglo XxI, donde los diarios no son sino eso: un recuento terrible y desconsolado de muertes anónimas? ${ }^{3} \mathrm{La}$ diferencia de nuestra modernidad quizá consista en el grado de espectacularidad con que estas muertes aparecen. Y digo aparecen y no sorprenden, porque el elemento sorpresa ha desaparecido de nuestro vocabulario, de nuestra vida cotidiana. La

${ }^{2}$ Todas las versiones originales de las citas a los Diarios intimos [Journaux intimes] provienen de Spleen de Paris.

${ }^{3}$ Término que, por cierto, se instauró en el léxico mediático desde la Gran Guerra europea. 
muerte en masa ya no significa nada sino el acontecimiento cotidiano, que uno mira de reojo para pasar a la siguiente página o para ejercer, con todo el poder que nos ha dado la tecnología, el zapping, ${ }^{4}$ que nos coloca en la posición de quien controla el mundo con un solo movimiento del mando remoto. Las últimas guerras, además, nos han abierto todo un campo espectacular frente al cual ya no hay hombres que mueren, mujeres y niños despedazados por las bombas, ciudades devastadas en las que no se asoma, ni por casualidad, una gota de sangre o una lágrima derramada. No, nuestra majestuosa modernidad nos ha inmunizado contra la muerte, somos simples espectadores que miran en la oscuridad la desaparición de generaciones, de culturas y de vidas sin que nuestros ojos choquen con la realidad, ésta es simplemente una "experiencia" más que nos brinda la tecnología moderna. Ver morir sin ver la muerte, ver desfallecer un país y su cultura sin apenas darnos cuenta. Ya lo decía Benjamin en su artículo de 1936, "El narrador", citando al fundador de Le Figaro: "el incendio en un techo en el Quartier Latin les es más importante que una revolución en Madrid" (Benjamin, "El narrador", 116). Y ¿no es acaso esto lo que vivimos todos los días? Sin embargo, es necesario distinguir de qué modernidad se trata. Lo que Baudelaire y Blanqui experimentan, cada uno desde su "trinchera", es justamente el inicio de este empobrecimiento de la experiencia, como lo llamará más adelante Benjamin.

Pero, ¿qué es exactamente lo que ven estos pensadores?, ¿por qué el malestar? Ciertamente, hay en ellos una conciencia de la pérdida de un tipo específico de experiencia, un melancólico mirar hacia atrás donde las cosas parecían tener un sentido y el universo un principio de identidad. La Gran guerra, en el caso

\footnotetext{
${ }^{4}$ Palabra muy socorrida actualmente, mediante la cual se designa al salto frenético entre programas de televisión. La expresión correcta en inglés para designar esta actividad es flip channels.
} 
de Benjamin, vino a dar el golpe final, cuando los soldados volvían del campo de batalla sin una experiencia que contar. Y ese silencio que Benjamin no pudo ver en 1945, aunque lo vislumbró, se convirtió en una tumba donde quedaron sepultados los restos de una civilización de la cual nadie quería, en principio, saber nada. Sin embargo, este final no fue intempestivo, se dejó ver en cada uno de los gestos del pasado, en la brutalidad colonizadora del siglo XIX, en las calles de las grandes ciudades donde el obrero fatigado, la suciedad y las prostitutas pululaban como ratas hambrientas. Al menos así lo percibe la sensibilidad del poeta, que sabe ahora que habrá que cantarle a la muerte, a los desechos de la ciudad y, con ellos, a sus habitantes, que han sido arrojados a las calles. Son ahora la prostituta, el hambriento, el obrero con la carga de fatiga a cuestas quienes pueblan desde ya su horizonte poético, quienes habitan en lo más profundo de su alma de poeta. En "Crepúsculo de la tarde", Baudelaire escribe:

[...] -Es la noche quien serena

los espíritus que devora un dolor [salvaje,

el sabio obstinado cuya frente se [entorpece, y el obrero encorvado que recobra [su cama. Mientras tanto los demonios malsa[nos en la atmósfera se despiertan pesadamente, como [gentes de negocios, y golpean al volar los postigos y el [alero.

A través de los destellos que ator[menta el viento la Prostitución se enciende en las [calles; como un hormiguero abre sus [salidas,
[...]-C'est le soir qui soulage

Les esprits que dévore une douleur

Le savant obstiné dont le front [s'alourdit,

Et l'ouvrier courbé qui regagne son [lit.

Cependant des démons malsains [dans l'atmosphère S'éveillent lourdement, comme des [gens d'affaire,

Et cognent en volant les volets et [l'auvent.

À travers les leurs que tourmente le [vent

La Prostitution s'allume dans les [rues; Comme une fourmilière elle ouvre [ses issues; 
por todos los sitios se abre un oculto

[camino

igual que el enemigo que intenta un

[ataque;

se mueve en el seno de la ciudad de

[fango

como un gusano que roba al

[Hombre lo que éste come.

[...]

Es la hora en que los dolores de los

[enfermos se recrudecen.

La sombría noche los toma por el

[cuello; terminan

su destino y van hacia la sima

[común;

el hospital se llena de nuevo de sus

[suspiros. - Más de uno

no vendrá más a buscar la sopa

[perfumada,

junto al fuego, a la noche, junto a un

[alma amada.

¡Todavía la mayor parte no han

[jamás conocido

la dulzura del hogar y ni jamás

[vivido!

(Baudelaire, Obra poética completa, 262.)
Partout elle se fraye un occulte

[chemin,

Ainsi que l'ennemi qui tente un

[coup de main;

Elle remue au sein de la cité de

[fange

Comme un ver qui dérobe à

[l'Homme ce qu'il mange.

[...]

C'est l'heure où les douleurs des

[malades s'aigrissent !

La sombre Nuit les prend à la

[gorge; ils finissent

Leur destinée et vont vers le gouffre

L'hôpital se remplit de leurs

[commun;

[soupirs. -Plus d'un

$\mathrm{Ne}$ viendra plus chercher la soupe

Au coin du feu, le soir, après d'une

$$
\text { [parfumée, }
$$

[âme aimée.

Encore la plupart n'ont-ils-jamais-

[connu

La douceur du foyer et n'ont jamais

[vécu!

(Baudelaire, Obra poética completa, 263.)

La teoría de la alegoría benjaminiana, dejando de lado el carácter retórico específico de esta figura, escribe Bainard Cowan con gran agudeza, representa para el autor antes que nada un "tipo de experiencia" (Cowan, "Walter Benjamin's Theory of Allegory", 110). Y, de manera más concreta, una manera particular de mirar el mundo, de aprehenderlo, no como algo permanente, sino como algo en continuo movimiento, en permanente "transitoriedad", argumentando, en última instancia, que "este mundo no es una conclusión" (110). Pero la alegoría es más que eso, más que una forma de expresión, es una intuición 
del mundo que toma la forma del fragmento. Es quizás por ello por lo que Benjamin recoge del universo poético baudelaireano esta inédita manera de observar al mundo, fragmentariamente y, por qué no, melancólicamente.

En la última parte de su texto sobre el Trauerspiel (rechazado para su habilitación en la universidad por haber sido considerado totalmente "incomprensible"), Benjamin se detiene para describir con todo detalle su concepción de la alegoría. En ésta, Benjamin encuentra a esos autores que lo asediarán a lo largo de su vida: Baudelaire, Kafka y Proust. Por ello, al hablar de "El Cisne" de Baudelaire, Benjamin dirá: "Todo para mí se convierte en alegoría" (Cowan, "Walter Benjamin's Theory of Allegory", 110). Es sabido el interés de Benjamin por dedicar un libro a la obra de Baudelaire, que desafortunadamente quedó inconcluso. Sin embargo, el filósofo logra rescatar justamente esa nueva "visión del mundo", esa mirada alegórica con la que el poeta aprende a observar las calles, los prostíbulos, a sus habitantes, a los pepenadores, a los obreros harapientos producto de la modernidad; la masa anónima que puebla calles y avenidas, hasta proponer que "Prêter une âme à cette foule, tel est le rôle du flâneur" (Benjamin, Charles Baudelaire, 163). Qué mejor poeta para inspirar a un Benjamin preocupado a lo largo de toda su obra por el empobrecimiento de la experiencia: sea la del narrador, la del lenguaje caído, o la del pepenador y la prostituta que han entrado en la modernidad desnudos ya de esa aura que tantos lamentos arrancó a Benjamin, pero también al propio Baudelaire. En su Spleen de París el poeta describe, en el poema "Pérdida de la aureola", la experiencia de aprender a vivir sin ella. ${ }^{5}$

\footnotetext{
${ }^{5}$ Se sabe que existe otra versión de este mismo poema donde Baudelaire finalmente la recupera.
} 


\section{Pérdida de la aureola}

- Mi buen amigo, bien sabe usted que me causan pánico los caballos y carruajes. Pues bien, hace un momento, cuando atravesaba el bulevar a toda prisa, saltando entre el barro en medio de ese hirviente caos en donde la muerte acude al galope por todos lados a la vez, mi aureola, en un movimiento brusco, resbaló de mi cabeza y fue a parar al fango del empedrado. Me faltó valor para recogerla (Spleen de París, "Pérdida de la aureola", 113). ${ }^{6}$

¿Es acaso posible que Benjamin se inspirara en el poeta para regresar una y otra vez al aura perdida? No lo sé. Sin embargo, veo en ella una perspectiva sobre la vida, una praxis llevada a cabo por la poesía de Baudelaire, una de las más profundas fuentes de inspiración de su propia crítica a la modernidad. La alegoría como una manera nueva de ver el mundo no la inventó Benjamin, existía desde siempre, sólo que esta vez dicha figura se convirtió para el filósofo y crítico en algo mucho más complejo, en el cristal desde donde miró a la literatura, a la filosofía y, por sobre todo, a la crítica. En ese sentido, tanto el poeta como el crítico, como escribe Benjamin en "El París del Segundo Imperio en Baudelaire", se encuentran en revuelta más o menos sorda contra la sociedad, enfrentados a una vida precaria (Benjamin, "El París del Segundo Imperio", 37). Pero es justamente esta vida precaria la que les otorga "a cambio" esa especie de tercer ojo con el cual son capaces de mirar de cerca, no sólo los avances de la modernidad, sino justamente la precariedad de la vida moderna. Por ello, tanto en Baudelaire como en Poe,

6 "Mon cher, vous connaissez ma terreur des chevaux et des voitures. Tout à l'heure, comme je traversais le boulevard, en grande hâte, et que je sautillais dans la boue, à travers ce chaos mouvant où la mort arrive au galop de tous les côtes à la fois, mon auréole, dans un mouvement brusque, a glissé de ma tête dans la fange du macadam. Je n'ai pas eu le courage de la ramasser" ("Perte d'auréole", Spleen de Paris, 89). 
encontramos, por vez primera, a la masa como un sujeto nuevo en la poesía lírica y en la narrativa (Benjamin, "Sobre algunos temas en Baudelaire", 141-142). Por ello, en consecuencia, la calle ocupará necesariamente un lugar de primera importancia. Lugar donde deambulan los "desahuciados" de la sociedad, será también el espacio donde el flâneur encontrará su habitat; la calle se convertirá, al final de sus vidas (la del poeta y la del filósofo) en una especie de refugio en medio de la multitud. Sus vidas y sus obras quedarán entrelazadas con el mundo de los bajos fondos: el borracho, el pepenador, la prostituta. A ellos cantará Baudelaire, como nadie lo había hecho antes:

EL VINO DE LOS TRAPEROS ${ }^{7}$

Se ve un trapero que viene, [meneando la cabeza chocando y dándose contra los [muros como un poeta, $\mathrm{y}$, sin tener cuidado de los [polizontes, esos sujetos, explaya todo su corazón en [gloriosos proyectos.

\section{$[\ldots]$}

Sí, estas gentes hostigadas por [penas domésticas, molidas por el trabajo y

[atormentadas por la edad, derrengadas y doblándose bajo un [montón de desperdicios, vómito indefinido del enorme París.
LE VIN DES CHIFFONNIERS

On voit un chiffonnier qui vient, [hochant la tête, Butant et se cognant aux murs [comme poète,

Et, sans prendre souci des

[mouchards, ses sujets, Épanche tout son cœur en glorieux

\section{$[\ldots]$} [projets.

Oui, ces gens harcelés de chagrins [de ménages,

Moulus par le travail et tourmentés

Éreintés et pliant sous un tas de [par l'âge, [débris,

Vomissement confus de l'énorme

[Paris.

(Baudelaire, Obra poética completa, 291.)

${ }^{7}$ La traducción es mía. 
Ahora bien, como decía líneas atrás, esta visión poética de la modernidad que se atreve a cantarle a los obreros, a los borrachos y vagabundos no le viene a Benjamin sólo a través del poeta sino del revolucionario, del hombre de acción que fue Blanqui. Es aquí donde confluyen las tres B: Benjamin, Baudelaire, Blanqui. Es este último el que completará la escena del "progreso" de la modernidad. De la misma manera que encontramos en Benjamin una aguda crítica a la idea del progreso, Blanqui ya la habrá puesto en duda un siglo atrás. Sabemos que el filósofo no nos ha dejado un trabajo sistemático que se preste a doctrina alguna, ni siquiera a una escuela (no obstante la cantidad de benjaminianos que proliferan en el mundo), sino una serie de acertijos que nos llevan a internarnos en un mundo muy parecido al de Kafka. Me atrevería a decir, al igual que cuando Benjamin se refiere a Blanqui, que aquel no remite a un nombre de persona sino a una posibilidad existencial a un, llamémosle, "estilo benjaminiano". Como diría el mismo Blanqui, “¡un poco de pasión y las doctrinas más tarde!” (Blanqui, "L'Éternité par les astres", 25). 


\section{REFERENCIAS}

Baudelaire, Charles, Obra poética completa, Barcelona, Ediciones 29, 1977.

_- Spleen de Paris, Journaux intimes, Choix de maximes, Consolantes sur l'amour, Paris, Cluny, 1987.

_-, Spleen de París, Madrid, Visor, 1998.

—, Diarios íntimos, México, Ediciones Coyoacán, 1999.

_-, Baudelaire. Correspondencia general, Buenos Aires, ParadisoFondo de Cultura Económica, 2005.

Benjamin, Walter, The Correspondence of Walter Benjamin, Chicago, The University of Chicago Press, 1994.

__, "El narrador", en Para una crítica de la violencia y otros ensayos. Iluminaciones IV, Madrid, Taurus, 1999a, 111-134.

__ "El París del Segundo Imperio en Baudelaire", en Poesía y capitalismo. Iluminaciones II, Madrid, Taurus, 1999b, 21-120.

_- "Sobre algunos temas en Baudelaire", en Poesía y capitalismo. Iluminaciones II, Madrid, Taurus, 1999c, 121-170.

_- Charles Baudelaire. Un poète lyrique à l'apogée du capitalisme, Paris, Payot, 2002.

_- Tesis sobre la historia y otros fragmentos, trad. Bolívar Echeverría, México, Contrahistorias, 2005.

_- Libro de los pasajes, Madrid, Akal, 2006.

Blanqui, Auguste, "L'Éternité par les astres", en Maintenant, il faut des armes, Paris, La Fabrique éditions, 2006, 318-382.

_., Maintenant, il faut des armes, Paris, La Fabrique éditions, 2006.

CowAn, Bainard, "Walter Benjamin's Theory of Allegory", New German Critique, 22, 1981, 109-122. 